\title{
Social Security and Fairness in a Changing World
}

\author{
Dirk J. Wolfson \\ Department of Public Administration, Erasmus University Rotterdam, Rotterdam, The Netherlands \\ Email address: \\ dwolfson@xs4all.nl

\section{To cite this article:} \\ Dirk J. Wolfson. Social Security and Fairness in a Changing World. Journal of Public Policy and Administration. \\ Vol. 5, No. 3, 2021, pp. 62-71. doi: 10.11648/j.jppa.20210503.11
}

Received: May 7, 2021; Accepted: June 7, 2021; Published: June 16, 2021

\begin{abstract}
People are not alike. Hence, the basic difficulty in a democracy is that elections may determine the general stance of policy, but do not provide operational information on how to customize for diversity in the business of governance in a world that in changing after the crash-landing of covid-19. This background calls for a restructuring of social security, and introduces a situational mode of contracting that deals with asymmetric information in principal-agent theory when perspectives of suppliers and beneficiaries of public support may differ. Its core question is how to combine customized support for diverging needs, capabilities and employability, as recognized by caseworkers, with customized obligations on the part of beneficiaries, in co-production between civil servants and individual clients or their representative organizations. Situational contracts match demand and supply in social support throughout the process of public policymaking and delivery, and in horizontal relations with network partners as well. Inspired by recent findings from behavioral public administration, the situational mode deals with complexity in a consensual principal-agent model. This paper claims that there is scope for transaction as a tool to reveal, from the actual decisions taken, how we can match efficiency and fairness in a mode of situational contracting as developed below.
\end{abstract}

Keywords: Diversity, Discretion, Complexity, Responsive Policymaking, Situational Contracting

\section{Introduction}

Situational contracting is an incentive-compatible mechanism design. It builds a case for collaborative public governance, as an arrangement in which stakeholders in demand and supply of public services are engaged in a consensus-oriented process geared to further trust - the relational element, Carson et al [10] - and to discipline behavior.

Note that principal-agent theory as a mode of governance is sometimes associated with cases in which information asymmetry limits the grip of the principal on self-serving or otherwise uncooperative agents Scharf [44]. Jones [26], however, argues forcefully that this approach is unsubstantiated, leads to a formalistic control perspective, and kills creativity. Moreover, as Breton [7] points out, professional agents may be better informed than clients about solutions to improve employability that, moreover, reveal preference in the trade-off between efficiency and fairness.

The situational contract is an application of what Cornelisse and Thorbecke [12] call an exchange configuration, a mode of governance in which the three basic elements of transactions are brought together:

(1) The item or content of what is exchanged: personalized pubic support, for instance, against specified inputs of the beneficiaries to improve their situation,

(2) The attitudes and capabilities of the actors engaged in decisions, and

(3) The cultural and legal environment and the socioeconomic, political, legal and climatological situation, as the elements that determine the life chances of people Dahrendorf [13], Wolfson [60].

For content, the general idea behind a situational approach - as visualized in the scheme below - is that it integrates bottom-up information on capabilities and needs with topdown initiative and discretion in a responsive co-production and political guidance from the top. The scheme shows how situational contracting may facilitate interactive and collaborative principal-agent relations, possibly fortified by horizontal inputs from network partners as well. Rights, benefits and corresponding obligations are broadly structured by law or, internationally, in treaties, but, in the process of implementation, interventions are detailed for functional 
diversity in a situational mode, in recognition of the mutual dependence of principals and agents in finding appropriate solutions.

In layer 1 of the scheme, politicians develop programs that, presumably, are based on a mandate obtained from citizens who have swapped support for electoral promises. Granted, this is a rather heroic assumption from the core of political theory about the way a democracy works, but that is exactly what the subsequent steps of civic involvement in collaborative government try to lend more credibility.

In layer 2, public management starts when political principals interact with senior civil service in developing policies, drafting legislation and protocols of good practice for responsive policymaking and implementation. This may be done, as well, when consultation with network partners in other departments of governance, jurisdictions or voluntary organizations representing citizens in dealings on the supply side.

Next, in layer 3, senior staff, now in their role of administrative principals, approve periodic mandates and budgets for situational implementation developed bottom-up by professional agents in or, possibly, outside their own organization on the basis of their experience in delivery. Mandates and budgets enable case workers to customize support in layer 4 for differences in needs, capabilities, and individual preferences of beneficiaries and to convert available resources and opportunities into actual functionings Sen [48]. To that effect, professionals in implementation need degrees of freedom to use their judgement in the application of rules and regulations, on the basis of comply-or-explain. In this process, the situational mode reveals the scope and willingness of parties in supply and demand to cooperate. The combination of mandating with learning, belief change and innovation, as crucial conditions for collaborative governance (Emerson [15]) and Leach et al [30] help to align incentives, furthers trust and creates scope for innovation. Layer 4 of actual delivery emancipates the street level bureaucrat; it presents the caseworker not just as the interface between citizen and state, but also as the face of the state. This is more than a play with words: as Atkinson [33] points out, the human service element in co-production adds to the quality and productivity of solutions. At this layer, individual exclusion on the demand side is, of course, not possible with regard to pure public goods in open access. This means that voluntary associations and advocacy coalitions may have to stand-in earlier on in the policy arenas of layer 2; their input, however, may be excluded in case of uncooperative behavior.

Layer 5 of the scheme provides feed-back from results in learning loops of adjustment and continuous legitimation. It is held that a mode of relational and contextual or situational contracting reveals preference in a setting of collaborative governance. Note that - throughout the process, arrows point up and down or sideways, signaling the interactivity of policymaking and delivery.

While market coordination depends on excludability to identify preference and to recover cost, public governance may offer public goods where exclusion and market solutions are impossible (in case of flood control, for instance) or not wanted. The same goes for quasi-public goods where exclusion is possible but socially inefficient, for instance too costly, or inconsistent with distributional concerns. The situational mode grants discretion to customize public support for diversity in the mix of education, skills, and social background (Calmar Andersen [9]. Customization and responsiveness endeavor to fit facilities to individual needs, and excludability deals with uncooperative behavior that clients might try to play. Degrees of freedom for professional agents in delivery may be withdrawn, or access of claimants to public facilities denied in case of uncooperative behavior or failure to deliver on the terms of the contract.

Excludability is a standard requirement of contract theory (Cornelisse and Thorbecke [12]. The risk of exclusion runs all the way, layer by layer, from losing a political majority or failure to build a coalition to the degrees of freedom for professionals in delivery to customize solutions, or in withholding access to facilities in case of uncooperative attitudes on the demand side, and horizontally, if network partners do not play game. In short, the risk of exclusion may take the guile out of self-interest Williamson [59], and contracting creates transparency throughout the entire process of policymaking and delivery, striking a balance in the familiar tension between technical competence and procedural legitimacy with an emphasis on public involvement and justification, as 'good governance' should Rose-Ackerman [43].

The essence of the situational approach is that the combination of mutual dependence in achieving results and excludability in principal-agent relationships creates scope for incentive-compatible and sustainable solutions. Mutual dependence links the agency of professionals in public support with political guidance; it answers the question why public managers would choose tools of collaborative governance (Scott and Thomas [46]). Clearly, contracts may be 'incomplete' McBeath [33], and there will be a trade-offs between complexity and allowance for diversity (Calmar Andersen [9]. Yet, basic behavioral assumptions are

(1) That political principals are prepared to accommodate diversity and value the expertise of agents in delivery,

(2) That public managers (administrative principals) and case workers in delivery appreciate degrees of freedom to provide the best possible fit between demand and supply, and

(3) That network partners and individual beneficiaries or their representatives want to be heard and humored as well.

Customization in implementation and guidance on the basis of comply-or-explain involve the parties concerned in a halfway house between the creativity of agency and the rigor of regulation, since rules remain paramount in situations where no discretion is granted. A crucial contribution of the situational mode, moreover, is that the terms of trade not just reveal the trade-offs between the criteria of good governance, but are presumed and monitored to further their acceptability and legitimacy as well. As noted before, situational contracting clarifies to what extent a society is prepared to trade efficiency for fairness and sustainability. 
In short, the scheme above shows how situational contracting, layer by layer, can provide a framework to customize for diversity in an appropriate conditionality of access to support, vertically in hierarchies, and horizontally in networks. Appropriateness also means that the transaction costs of deliberation should stay below the alternative social costs of hard and fast rules imposed 'from above'. The mechanism involves all the relevant parties interactively, recognizing them as creative agents, and satisfies the criterion that governance structures 'must not be conceptualized as simply placing a constraint on human agency, but as enabling' Giddens [17], as well as the claim that human freedoms include the liberty to be involved in defining and pursuing one's goals Sen [50].
Summing up, situational contracting furthers trust in government. It facilitates and encourages the agency and cooperative attitudes of professionals, citizens and their voluntary associations in public service delivery. Mandates and content reveal the actual terms of trade between criteria of good governance, such as respect for human dignity, freedom, efficiency, fairness and sustainability.

Compared with the more complex 'black boxes' of collaborative governance explored in the literature (see 3Thompson and Perry 200 [53], Scott and Thomas [46], the situational mode is based on degrees of freedom to customize solutions within a given and monitored structure of decisionmaking, and inspired by findings from the behavioral literature as elaborated upon in Parts 3, 4 and 6.

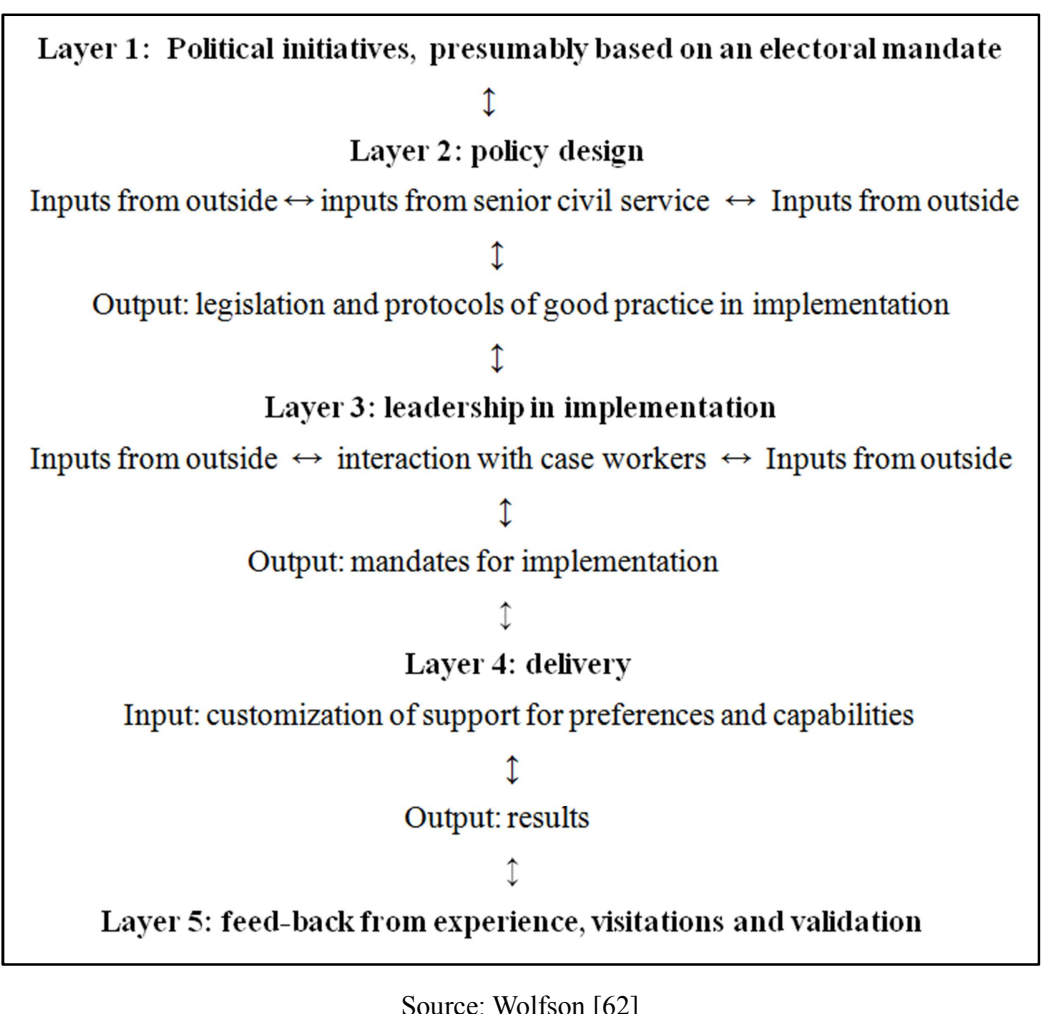

Figure 1. Situational contracting in a layered and interactive approach.

\section{Notes on Method, Normative Considerations and Behavioral Aspects}

In terms of method, strands of law, political theory, welfare economics, game theory and a newly emerging field of behavioral public administration Tummers et all [55] are interwoven in the situational mode. In a legal sense, it draws on a calibrated combination of public law and common contract law. Public control moves from a 'compliance' orientation in which success is measured by conformity to rules, toward a 'performance' orientation, in which the focus is on reasonability in the achievement of goals Noonan [37], and on reputation in solving problems Busuioc [8], in what
Mascini [31] calls a 'socio-legal approach to discretion'. Revealed preference, as deduced from contracts concluded, reduces information asymmetry and enables customization for individual needs, while excludability dissuades recourse to uncooperative games. The trades in the situational contract are geared to achieve an incentive compatible mechanism that will get us closer to Nash equilibria: states in which all participants have an incentive to work out solutions. Individual protection is provided by exit options, such as appropriate job offers in case of unemployment, allowing for second opinions or access to a court of law, and by periodic visitations as checks and balances. The latter play a crucial role, moreover, in minding Agranoff's lesson [1] that 'Despite the cooperative spirit and aura of accommodation in collaborative efforts, networks are not without conflicts and power issues'. In particular, the presumption introduced 
earlier that the deals concluded are indeed acceptable and legitimate requires close monitoring. Remember, on the other hand, that the alternative risk of information asymmetry in traditional bureaucracy may lead to 'all checks and no balances', as The Economist once punned.

Governments, generally, spend a large share of their budget on excludable facilities in areas such as education or health care. Claims are controlled by engaging beneficiaries to reveal their needs and capabilities along with their willingness to accept ensuing obligations in order to gain access to opportunities offered. The combination of conditionality with excludability is a crucial element of the mechanism design here presented. In case of pure, nonexcludable public goods, situational contracting concentrates on negotiations with advocacy coalitions, such as labor unions or environmental NGO's to articulate the preferences of their constituency.

As a collaborative format, situational contracting fits in the integrative framework described by Emerson et al [15] in which outcomes are driven by leadership, shared or compatible motivations, principled engagements and a capacity for joint action. This article emphasizes its behavioral aspects, exploring how the situational mode is based on contributions from Breton [7]), Bénabou and Tirole [4], Dur and Zoutenbier [14], Tummers and Bekkers [55], Wolfson [64] and related authors that enrich our insight in public service motivation and the management of collaborative principal-agent relations. The situational contract is inspired by the recognition that rising levels of education in the rich part of the world and an upgrading of the competence of professionals in delivery provide capacity for joint action in a gradual transition towards a more deliberative style of governance, in what Sen [49] calls 'governance by discussion'. This allows for an emancipation of traditional, top-down bureaucracies into principal-agent relationships based on well-informed interaction and cooperation, both vertically - in the entire column of policymaking and implementation - and horizontally, in relations with network partners. Reciprocity is important for fostering mutual understanding and trust.

Professionals, in policymaking as well as delivery, are seen as typically able to customize solutions in a relational and situational or contextual response, and as motivated by challenges and results, rather than rules: they want to heal, to teach, to explore, to serve and protect human dignity, or whatever they are called for. They need degrees of freedom to do their thing and to sustain their reputation vis-a-vis different audiences (Busuioc and Lodge [8]. It follows that their incentive structure calls for trust management in an interactive social exchange conception of principal-agent theory and a coaching style of leadership, nursing intrinsic motivations Van Slyke [58], rather than for an authoritative and top-down 'principal knows best' version of traditional bureaucracy. Without the intrinsic motivation and pride of professionals, information asymmetry may lead to noncooperative games in which actors in both supply and demand may try to maximize their individual utility, rather than the common good.

Obviously, personalities matter, both on de supply- and the demand side of public services. Boone et al. [6] distinguish between 'externals' of a more fatalistic disposition who see little opportunity to control their lives by their own efforts, and 'internals' who are self-monitoring in internal control. The latter believe in their own capabilities, see themselves as active agents and tend to make more cooperative choices, particularly in repeated interactions or games. They are more disposed to show cooperative behavior and individual responsibility than the 'externals'. Recall, however, that Tuk et al. [54] caution for dissimilarity in interpersonal influence between principals and agents, particularly at the level of service delivery. They have a point, which calls for training in bedside manner for medical personnel and, more generally, for interviewing skills throughout the realm of social services. On the strength of behavioral research reported on here and a further discussion in Part 5, this paper suggests that openness and interaction in a coaching approach on the part of the principal, using nudges, deliberation and incentives to entice 'externals' into participation as well, will generate trust in fairness and more cooperative attitudes (Pruitt and Kimmel [42]; Boone [6]. Whether - and to what extent - cooperative attitudes in a situational setting will indeed drive out risks of moral hazard and conflict of interest in principal-agent relationships is, of course, an empirical issue, but the evidence on attitudes referred to above is encouraging. Nevertheless, good intentions and commitment need monitoring and political guidance, and so everyone's response has to be firmed up in an incentive compatible mechanism design [Maskin [32], Myerson [35]: and monitored by the responsible principal. More on public service motivation and personality traits in Oberfield [38] and in the discussion (Part 5).

Normative considerations are that openness and interaction in a multi-actor perspective are hallmarks of democracy that deserve support. Human dignity and the sovereignty of citizens remain the core of the situational mode and a communicative democracy that reveals willingness to accept policies and promotes transparency and fairness in the distribution of burdens and benefits through deliberation, persuasion and consensual adjustment. Distributional issues are dealt with in terms of capability, a notion referred to in layer 4 of the scheme in Part 2 and introduced by Sen [48-50] who, as noted, interprets well-being as not exclusively associated with affluence but with an individual's capability to convert resources and opportunities into actual functionings. He introduced a research program exploring how people differ in their physical, cognitive, psychological, social and political capabilities for this conversion. He considers capabilities, functioning and the protection of human dignity the prime objects and metric of fairness in distribution, along with the distribution of resources and opportunities. Sen's capability theory has triggered a vast literature; there is even a Society and a scholarly journal entirely dedicated to its further development Wolfson [61] and [62]. Lacking, however, is a mode of gathering 
information for its implementation, as provided by the situational mode.

\section{Claims, Feasibility and Limits}

Situational contracting (1) can cope with diversity in needs and capabilities, (2) assigns everyone's role in sharing responsibilities when providing public support, (3) generates vital information to improve the match between demand and supply, (4) creates voice options in an interactive style of management, (5) reduces asymmetric information by activating the sanction of exclusion to discourage uncooperative games, (6) relinks policy making and administration, (7) fosters involvement with the common good, creating clarity, commitment and willingness to accept solutions (Conklin 2006: [11]), (8) structures an incentive compatible process of implementation as an essential element in the credibility as mechanism design; Hurwicz [20], moreover, (9) is feasible to the extent that marginal social costs of contracting do not supersede the social costs of regulation as an alternative. (10) Note, moreover, as its core contribution, that it reveals and, hopefully, helps to rationalize the preferences of the contracting parties in an ongoing dialogue, but differs from the market mode in that its terms of trade are monitored in the political process and creates a halfway house of comply-or-explain between the rigor of regulation and the creativity of agency.

Yet, there is no need for situational contracting if regulation is unambiguously accepted (as in keeping right or left - in traffic). If not, the situational mode is available where access of citizens to individualized benefits is excludable, and conditional on ascertainable efforts to limit claims to what is considered appropriate.

Throughout the process described above, access to excludable public benefits is contingent on reasonable efforts to cooperate. Similarly, degrees of freedom for professionals in delivery to apply a 'reasonable man standard' in interpreting their mandates may be revoked and agents reassigned to lesser responsibilities in case of an unsatisfactory commitment or performance. While inputs from the private sector may be welcomed in the process of implementation, the situational contract is not a publicprivate partnership, as responsibility and accountability for the system as a whole remains with political principals. Periodical visitations are to avoid that conditionality of access would corner legitimate demands for public support. Situational contracting is a dynamic mechanism design, in which both professional agents and beneficiaries are given a voice in the process of implementation with a view to generating loyalty and a cooperative attitude. Moreover, the situational mode accommodates the behavioral perspectives and commitment of a more and more professional civil service and recognizes differences in capabilities of beneficiaries to deal with the complexities of choice.

Behavioral research tells us that people may have difficulty in sorting out where they want to go and what they want to get. Kahneman et al [27] show how users of optional public services differ in their ability to make choices. Hence, service providers should act as 'facilitators of choice', in a coaching style of communication (Gailmard and Patty 2007; Jilke [25]; Jones 26]. At first sight, framing capabilities, opportunities and functionings may smell of soft paternalism in a redistributive concept (Schnellenbach 45]. That remains to be seen: the object is not to impose preferences but to start a dialogue clarifying the need and the options for a timely adjustment of human capital to a changing world, so there is a dimension of allocative gains as well.

\section{Discussion}

The method and behavioral aspects introduced in Part 3 and the applications to be discussed in Part 6 deserve a further discussion from a perspective of public administration and relational management (Carson et. All [10]; McBeath et al. [33], now that the mechanics of the situational contract are explained.

Presumably, prisoner's dilemmas and uncooperative games will be less virulent in the public sector when contracts are made up interactively. With regard to the effectiveness of the state in its role as a provider of social services, Bénabou and Tirole [4] explore the danger that authoritative and top-down management by principals drives out intrinsic motivations of professional agents. They formalize a large array of conditions under which poorly informed styles of empowerment and monitoring on the part of principals may have a negative impact on morale and actually impair the performance of their agents (2003: 490). Clearly, professional ethic may be alienated if principals play favorites, underplay the trust-effect or rub their professionals wrong in other ways (Tummers et al. 55].

While noting the need to extend their behavioral analysis to groups, Bénabou and Tirole [4] focus primarily on individual responses that may differ widely across a situational regime of policymaking and implementation. This article concentrates on comparing the overall group results of the situational mode with performance in traditional topdown bureaucracies. In modern democracies, professional agents in either public or semi-public institutions are usually working in a team, a group (or even a guild). They are presumed to be inspired by public service motivation, job satisfaction, professional pride and recognition on the part of their peers. While it is acknowledged that, within and between teams, motivations, capabilities and responsibilities may differ, it is the prevailing attitude and the overall outcome that count.

In that connection, Besley and Ghatak [5] emphasize that workers are heterogeneous in their 'mission preference', and tend to sort to organizational formats they share a mission with. Consequently, people who go for an easy life without mission-driven responsibilities will look for employment in administrative routines outside the realm of situational contracting that do not require judgement in customization. Research on the basis of extensive surveys by Dur and Zoutenbier [14] confirm this sorting hypothesis. They find 
that workers who exhibit both altruism and confidence in the political system are significantly more likely to end up working in the public sector', and note that altruism and mission alignment are mutually reinforcing.

Against this background, Parts 2 and 3 examined the potential of a coaching style of management in which extrinsic incentives are geared to activate intrinsic motivations by fostering the trust-effect and creating scope for improving capabilities [58]. On the whole, it transpires that learning about the motivations of public sector employees and sorting accordingly can contribute to a better understanding of organizational performance in the public sector [Dur and Zoutenbier 14].

Clearly, there are transaction costs to be accounted for in the transition to a situational mode, which calls for a gradual introduction and for patience in developing new, but more inspired approaches of dealing with complexity. But, here again, sorting may help out. In the social security cases to be discussed in Part 6, clients are sorted at intake, according to their (presumed) 'distance to the labor market', which allows case workers to specialize in differentiated mandates. At the end of the day, the traditional equilibrium condition applies that marginal transaction cost should remain below the marginal social cost of one-size-fits-all regulation superseded. Fairness, moreover, requires that exit options - such as employment opportunities as a way out of reliance on social security - are realistic, in terms of a 'reasonable person standard' of common law. In short, the situational mode is presumed to satisfy the fundamental conditions of exit, voice and loyalty [Hirchsman 19].

On the sunny side, however, feed-back from situational contracts generates a wealth of endogenous information about concepts, objectives, mandates, diversity and implementation. Once politicians get support for an incentive- compatible and dynamic mechanism design of openness and interaction, a gradual process of transformation will have to start in which self-monitoring professionals get more leeway, and traditional, nonentrepreneurial bureaucrats may have to be reassigned to more routinized duties, especially now that covid-19 calls for restructuring both social security and the labor market.

\section{Applications}

An early example of the situational mode at the macrolevel is the way in which the IMF arranges stabilization programs with member countries. It offers customized support on the basis of a letter of intent that specifies the content of the exchange configuration - in this case the structural adjustments to be made by the counterpart - "to ensure the revolving nature of the Fund's resources" (they want their money back, eventually). On its own account, the European Council of Ministers, the political executive of the $\mathrm{EU}$, recently introduced individualized situational contracts in 'home-grown partnerships' with member countries as a way of specifying plans for structural adjustment. Elsewhere, I develop the case for situational contracting in dealing with the complexities of negotiating transnational solutions for environmental sustainability (Wolfson [62].

At the national level, situational contracting was pioneered in the Netherlands, in a major overhaul of the social security system in 2003 that shifted the primary focus from the provision of benefits to prevention and reintegration Wolfson [60]. Employers are now obligated to contract private manpower agencies to monitor health and safety in working conditions and assist individual workers who lose their job. The agencies are to help in the situational mode to retool if necessary and find appropriate employment. They provide a competitive facilitating interface serving customers (employers), claimants (employees), and political principals (who retain responsibility for the way the system works). A public agency provides insurance, funding for retooling programs and operates as a 'gatekeeper' deciding on access to social security if credible efforts to find employment fail, or are waved on situational grounds, such as serious and lasting disability. Decisions may be challenged by second opinions and are contestable in a court of law, which uses a protocol of best reintegration practices as referred to in Part 3 as a frame of reference.

The new approach replaced rule-based but asymmetrically informed regulation by well-informed discretion. The inflow in disability schemes, for instance, declined from almost 120.000 persons in 2000 and 2001 (the years of the 'announcement effect') to less than 25.000 in 2006 and 2007, while over the period 2000-2008, the employment rate increased from 72.9 to 77.2 per cent, in Europe only second to Denmark. Results collapsed when demand for labor fell out in 2009 as a result of the global financial crisis, but were beginning to pick up apartment were arranged by the city's social services, and they could take home their used furniture. After five years, the project was peer-reviewed as effective and selected for rolling out and structural funding. again as of 2015, when the human service element (layer 4 in the scheme) was intensified [Noben et al. 36].

In recent years, moreover, the Dutch government introduced bottom-up impulses in a range of political transactions in areas such as welfare, income policies, pensions, housing and environmental strategy, committing the public and private sector network parties concerned in coalitions of the willing on a shared vision before bringing a policy package to parliament for ultimate approval. Euwals et al. [16] and Wolfson [60] provide more institutional and empirical details. Similar approaches are developing elsewhere [2] Ansell and Gash 2007; Prins [40]; McBeath [33]).

More generally, the situational approach brings order in complexity, as it reveals and aligns preferences and provides grounds for sanctioning uncooperative behavior. Yet, it has its limitations as well. Where individual exclusion remains impossible, or ineffective (as in the case of epidemic damage control), representation of citizens may remain delegated to experts and advocacy coalitions that may have a better insight in diversity than traditional bureaucracies. They too, however, are kept in check by policy competition, 
independent evaluation or even exclusion in case of uncooperative behavior. Nevertheless, while situational thinking holds a promise of more appropriate and effective public governance, it has to be admitted that globalization has its downside in diminishing public agency, with not just banks growing too big - and too powerful - to fail, but also in eroding political control over other large pressure groups.

A case in point are the difficulties in coming to grips with the management of environmental degradation. Note that the design of sustainable development does not pose wicked problems in the sense that we would not have sufficient information or properly designed solutions. On the contrary, a wealth of research shows that transition management towards a more sustainable development requires more efforts in mitigation of adverse effects than presently undertaken and that the cost of adaptation to its consequences will rise exponentially if we do not rise to the occasion [47]; IPPC 2014). Commitments made towards the Paris Conference on Climate Change of 2015 still need a lot of firming up, in spite of the fact that the Stern Review shows that the cost of not dealing with global warming, for instance, are a multiple of curbing it below a cap of 2 degrees Celsius. The case shows the crucial importance of political will to accept responsibility.

Nevertheless, the situational approach has a potential in unravelling real wicked problems as well, if the relevant parties are willing to find a solution. In Rotterdam, the 'wickedness' of multi-causality in long-term drug addiction in complex but hard to specify psychological disorders combined with unemployment, homelessness, social isolation and criminality was recognized conceptually for a long time. Yet, the scattered distribution of expertise and authority across a large number of institutions stood in the way of developing an integrated and evidence-based mode of treatment [Wolfson 62]. Then, some ten years ago, the five most relevant actors - a psychiatric hospital, the social services of the city, the local police, the probation authorities and a public housing agency - each made five professionals and some money and support staff available. They undertook a five-year closely networked and monitored experiment of 'dialogue mapping', a process of learning together and mapping the complexity of the project instead of succumbing to it, and crafted a shared commitment to finding integrated solutions (Conklin 11]. Staff and patients together developed an experimental rehabilitation program in the seclusion of the officers' hotel of a former army base, far away from the temptations of the big city. The Salvation Army helped to select the heavily addicted and provided used but acceptable furnishings. Situational contracts involved and incentivized the patients in a number of ways. If they made progress, for instance, they got nicer lodgings (the rooms were ranked the army way). Upon release, a job and an apartment was arranged by the city's social services, and they could take home their used furniture. After five years, the project was peer-reviewed and got structural funding. Obviously, there will always remain unknown causal drivers to be reckoned with in situational contracting. As Keele et al. [29] point out, the ultimate question in evaluation is not whether solutions work out or not, but why, which brings us back to the crucial importance of motivation and behavioral analysis.

Clearly, the situational contract is not a Magic Wand. In the dynamics of policymaking and implementation, uncooperative behavior of spoil sports and rent seekers, lack of political courage or plain stupidity will never be eliminated, but become more visible in the openness of an incentive-compatible mechanism design as a counterfactual.

\section{Summary}

A commitment to situational contracting brings us closer to answers on the key issues of social policy mentioned in the abstract: answers on who gets, pays for, or does what, when, where, how and why, in which who reveals the notions of fairness applied in the distribution of rights and obligations, what the outcome envisaged, again in terms of trade-offs between criteria of good governance, when identifies the intertemporal and where the spatial distribution, how specifies whether costs, benefits and compensations are in money or in kind, and why, finally, refers to the behavioral assumptions and distributional concerns.

In terms of results, the wicked multi-causality unemployment case at the end of Part 6 highlights the importance of working on a shared focus in averting a financial and moral crisis in social security, but its direct effect (it worked: less reliance on social support!) is - so far - not yet decomposed in the underlying drivers, as in the contribution of Keele et al. [29]: was it better training, more self-confidence in looking for work or something else (more demand for labor?). Finally, the relative success of the public health case - the better results than hoped for in dealing with drug addiction and homelessness - underlines the crucial importance of a shared commitment to find a solution. The actual terms of trade and the efforts realized in situational contracting. In terms of the normative trades between criteria of good governance as introduced in the abstract, situational contracting may signal and analyze outcomes of public interventions, but does not prescribe how politicians should deal, for instance, with differences in capabilities; it just reveals how the prevailing ideologies work out in a policymakers' welfare- or objective-function, like a democratic and open mechanism design should. In short: situational contacting is about revealed preference in demand as well as supply.

The long and the short of it, however, is that political and administrative principals can't look away anymore. In the situational mode, they will have to create coalitions of the willing and to give explicit guidance in (1) approving mandates, (2) sanctioning uncooperative behavior and (3) allowing for innovation in a mode of comply-or-explain, in order to capture the dynamism of interactivity and bottom-up information in policymaking as well as delivery. As noted, however, endogenous control will have to be fortified by external monitoring and visitation.

Novel modes of governance require a gradual introduction 
and take a while to catch on. Yet, in addition to the case studies reported on in Part 6, the overwhelming evidence in recent contributions from an emerging field of behavioral public administration referred to in Parts 3 and 6 shows the potential of an interactive and situational mode of contracting. Some of that evidence may be circumstantial, but improving targeting by gathering widely dispersed information about diverging desires, resources and capabilities of individual actors in society helps all the same to order complexity. Mutual dependency reduces the well-known behavioral risks of asymmetric information in traditional principal-agent relationships and meets the condition that mechanism designs make incentives compatible [35] Myerson 2008: 586 - 588)

The social security and the mental health cases in Part 6 focus on the relational aspects of public service and underscore that principals, case workers and clients are not just 'rational fools' (Sen [47] that are blindly pursuing selfinterest. They may be driven by sympathy, compassion and commitment as well.

A case in point are the difficulties in coming to grips with the management of environmental degradation. Note that the design of sustainable development does not pose wicked problems in the sense that we would not have sufficient information or properly designed solutions. On the contrary, a wealth of research shows that transition management towards a more sustainable development requires more efforts in mitigation of adverse effects than presently undertaken and that the cost of adaptation to its consequences will rise exponentially if we do not rise to the occasion (Stern et al. [51]; Commitments made towards the Paris Conference on Climate Change of 2015 still need a lot of firming up, in spite of the fact that the Stern Review shows that the cost of not dealing with global warming, for instance, are a multiple of curbing it below a cap of 2 degrees Celsius. The case shows the crucial importance of political will to accept responsibility.

\section{Conclusion}

The situational contract provides a powerful mechanism to combine responsive law-making in the provider state with political guidance for customized transactions that reveal the information needed to find incentive compatible solutions in public governance. Situational contracting works in situations of mutual dependence and brings us closer to an understanding of what makes the actors involved in policymaking and implementation tick. Yet, generating support for this approach may be easier in countries with a consensual principal-agent tradition, as in North-Western Europe, than in 'winner-takes all' political traditions. Nevertheless, accounting for diversity is a crucial condition for generating trust in governance, all the way from the micro-level of dealing with a growing inequality of income and opportunity [Piketty [39]; Putnam [41]; Milanovic [34] to the macro challenges of testing the acceptability of worldwide deals on sustainable development such as made in the Paris Conference on Climate Change. Its core contribution is that the situational contract reveals what politicians are intending to achieve, professional civil servants are trying to implement, and citizens are prepared to accept. In short, revealed preference orders complexity and improves targeting. Clearly, innovative modes of governance need time to prove themselves, but the recent empirical evidence from behavioral research presented in Parts 3 and 7 suggests considerable scope for a situational approach to relational contracting.

\section{Acknowledgements}

The author is grateful to Peter Cornelisse for his stimulating comments on earlier drafts.

\section{References}

[1] Agranoff, R. 2006. Inside collaborative networks. Ten lessons for public managers, Public Administration Review, 66: 50-6.

[2] Ansell, Chr. and Gash, A. 2007. Collaborative governance in theory and practice, Journal of Public Administration Research and Theory, 18: 543-571.

[3] Atkinson, A. B. 2015. Inequality. What can be done? Cambridge: Harvard University Press.

[4] Bénabou, R. and Tirole, J. 2003. Intrinsic and extrinsic motivation, Review of Economic Studies, 70: 489-520.

[5] Besley, T. and Ghatak, M. 2005. Competition and incentives with motivated agents, American Economic Review, 95 (1-2): 94-105.

[6] Boone, Chr., De Brabander, B. and Van Witteloostuijn, A. 1999 , the impact of personality on behavior, in five prisoner's dilemma games, Journal of Economic Psychology, 20: 343377.

[7] Breton, A. 1995. Organizational hierarchies and bureaucracies, European Journal of Political Economy, 11 (3): 616-626.

[8] Busuioc, E. M. and Lodge, M. 2016. The reputational basis of public accountability, Governance, 29 (2): 247-263.

[9] Calmar Andersen, S. and Moynihan, D. P. 2016. How leaders respond to diversity" The moderating role of information use, Journal of Public Administration Research and Theory, 26 (3): 448-460.

[10] Carson, S, J., Medoc, R. and Wu, Tao. 2006. Uncertainty, opportunism, and governance: The effects of volatility and ambiguity on formal and relational contracting, Academy of Management Journal, 49 (5): 1058-1077.

[11] Conklin, J. 2006. Dialogue Mapping: Building a Shared Understanding of Wicked Problems, Chichester: Wiley Publishing.

[12] Cornelisse, P. A. and Thorbecke, E. 2010. Exchange and Development, Cheltenham: Edward Elgar.

[13] Dahrendorf, R. 1979, Life Chances. Approaches to Social and Political Theory, London: Weidenfeld and Nicolson.

[14] Dur, R. and Zoutenbier, R. 2013. Working for a Good Cause, Public Administration Review, 74 (2),: 144-155. 
[15] Emerson, K., Nabachi, T. and Balog, S. 2008. An integrated framework for collaborative governance, Journal of Public Administration Research and Theory, doi: 10.1093/j0part/mur011.

[16] Euwals, R., De Mooij, R. and Van Vuren, D. 2009. Rethinking Retirement. The Hague: CPB.

[17] Giddens, A. 1979. Central Problems in Social Theory: Action, Structure and Contradiction, Berkeley: University of California Press.

[18] Hajer, M., and Wagenaar, H., eds. 2003. Deliberative Policy Analysis: Understanding Policy Analysis in a Network Society, Cambridge: University Press.

[19] Hirschman, A. O. 1970. Exit, Voice and Loyalty, Cambridge: Harvard University Press.

[20] Hurwicz, L. 1972. On incentives and the control of organizations, in McGuire, C. B. and Radner, R., eds. Decision and Organization, a Volume in Honor of Jacob Marshak, Amsterdam: North-Holland, 297-336.

[21] Hurwicz, L. 2008. But who will guard the guardians? (Nobel Lecture), American Economic Review, 98 (3): 577-585.

[22] Hupe, P. and Evans, T., eds., Discretion and the Quest for Controlled Freedom, Basingstoke: Macmillan 2000.

[23] IPPC 2014. (International Panel of Climate Change), Fifth Assessment Report (internet version).

[24] Jilke, S. 2015. Essays on the Microfoundations of Competition and Choice in Public Service Delivery, Ph. D. Thesis, Erasmus University Rotterdam.

[25] Jilke, S, Van Ryzin, G. G. and Van de Walle, S. 2015. Responses to decline in marketed public services: an experimental evaluation of choice overload, Journal of Public Administration Research And Theory, 26 (3): 403-420.

[26] Jones, B. D. 2003. Bounded rationality and political science: Lessons from public administration and public policy, Journal of Public Administration Research and Theory, 13 (4): 395412).

[27] Kahneman, D., Wakker, P., and Sarin, R. 1997. Back to Bentham? Explorations of experienced utility, Quarterly Journal of Economics, 112 (1): 375-405.

[28] Kahneman, D. 2003. Maps of bounded rationality, psychology of behavioral economics (Nobel Lecture), American Economic Review, 93 (5): 1449-1475.

[29] Keele, L., Tingley, D. and Yamamoto, T. 2015. Identifying mechanisms behind policy interventions via causal mediation, Journal of Policy Analysis and Management, 34 (4): 937-963.

[30] Leach, W. D., Weible Chr. M., Scott, R., Vince, S. N. Siddiki, and Calanni, J. 2013. Fostering learning trough collaboration: knowledge acquisition and belief change in marine aquaculture partnerships, Journal of Public Administration Research and Theory, 24 (3): 591-622.

[31] Mascini, P. 2000. Judges' Use of Discretion: A Socio-Legal Approach, in Hupe and Evans, op. cit.

[32] Maskin, E. S. 2008. Mechanism Design. How to implement social goals. (Nobel Lecture), American Economic Review, 98 : 567-576.
[33] McBeath, B., Carnochan, S., Stuart, M. and Austin, M. 2017). The managerial and relational dimensions of public-non-profit human service contracting, Journal of Strategic Contracting and Negotiation, 3 (2) 51-77.

[34] Milanovic, B. 2016. Global Inequality, Cambridge: The Belknap Press.

[35] Myerson, R. 2008. Perspectives on mechanism design in economic theory (Nobel Lecture), American Economic Review, 98 (3): 586-603.

[36] Noben, C. et al. 2015. Economic evaluation of a new organizational BTW intervention to improve cooperation between sick-listed employees and their supervisors: a field study, Journal of Occupational \& Environmental Medicine, 57 (11): 1170-1177.

[37] Noonan, K. G, Sabel, Ch. F., and Simon, W. H. 2009. Legal accountability in the service-based welfare state: Lessons from child welfare reform, Law \& Social Inquiry, 34 (3): 523-568.

[38] Oberfield, Z. W. 2010. Rule Following and discretion at government's frontline: continuity and change during organization socialization, Journal of Public Administration Research and Theory.

[39] Piketty, Th. 2014. Capital in the Twenty-first Century, Cambridge, Ma: The Belknap Press.

[40] Prins, R. 2009. Developing Well-Targeted Tools for the Active Inclusion of Vulnerable People. Synthesis Report on behalf of the European Commission.

[41] Putnam, R. B. 2015. Our kids. The American Dream in crisis, New York: Simon and Shuster. www.astri.nl/media/uploads/files/09505_Developing_welltargeted_tools_Peer_Review_Norway2.ppdf.

[42] Pruitt, D. and Kimmel, M. (1977). Twenty years of experimental gaming: Critique, synthesis, and suggestions for the future, Annual Review of Psychology, 28: 363-392.

[43] Rose-Ackerman, S. (2016). What does "Governance" mean? $\left(30^{\text {th }}\right.$ Anniversary Essay), Governance (early view) doi. 10.1111.

[44] Scharph, F. W. 1997. Games Real Actors Play. ActorCentered Institutionalism in Policy Research, Boulder: Westview Press.

[45] Schnellenbach, J. (2012). Nudges and norms: On the political economy of soft paternalism, European Journal of Political Economy, 28: 266-277.

[46] Scott, T. A. Thomas, C. W. 2016. Unpacking the collaborative toolbox: why and when do public managers choose collaborative strategies?, Policy Studies Journal (early view).

[47] Sen, A. K. 1977. Rational fools: a critique of the behavioral foundations of economic theory, Philosophy and Economic Affairs, 6: 317-344, reprinted in Sen, Choice, Welfare and Measurement, Oxford: Basil Blackwell 1982: 84-106. 1985 Commodities and Capabilities (Hennipman Lecture), Amsterdam: North-Holland Publishing Company.

[48] Sen, A. K. The Idea of Justice, London: Allan Lane.

[49] Sen, A. K. 2013. The ends and means of sustainability, Journal of Human Development and Capabilities, 14: (1) 6-20. 
[50] Stern, N. et al. 2007. The Economics of Climate Change. The Stern Review, Cambridge: University Press; also http://www.hm-treasury.gov.uk.

[51] Stiglitz, J. E. 2002. Information and the change in the paradigm of economics (Nobel Lecture), American Economic Review, 92, 460-501.

[52] Thomson A. M. and Perry, J. 2006. Collaboration processes: Inside the Black Box, Public Administration Review, Special Issue (December): 20-32.

[53] Tuk, M. et al., 2019. You and I have nothing in common: The Role of dissimilarity in interpersonal influence, Organizational behavioral human decision processes, 151: 49-60.

[54] Tummers, L. G. and Bekkers, V. 2014. Policy implementation, street-level bureaucracy, and the importance of discretion, Public Management Review, 16 (4): 527-547.

[55] Tummers, L. G., Bekkers, V., Vink, E. and Musheno, M. 2015. Coping during public service delivery: a conceptualization and systemic review of the literature, Journal of Public Administration Research and Theory, 25 (4): 1099-1126.

[56] Tummers, L. G., Olsen, A. L., Jilke, S. and Grimmelikhuijsen, S. G. 2016. Introduction to the virtual issue on Behavioral Public Administration, Journal of Public Administration Research and Theory, 16 (4): 527-547.
[57] Van Slyke, D. M. 2007. Agents or stewards; using theory to understand the government-non-profit social service contracting relationship, Journal of Public Administration Research and Theory, 17 (2): 460-501.

[58] Williamson, O. E. 1996. The Mechanisms of Governance, New York: Oxford University Press.

[59] Wolfson, D. J. 2012. Situational Contracting: Building Reciprocity between Rights and Obligations, Governance, 2012, 25 (4): 661-685.

[60] Wolfson, D. J. 2015a. Implementing Fairness in Social Policy, Journal of Human Development and Capabilities, (16): 272286.

[61] Wolfson, DJ2015b. The Political Economy of Sustainable Development: Valuation, Distribution and Governance, Basingstoke: Palgrave Macmillan.

[62] Wolfson, 202 Discretion from an economic perspective, in Hupe, P. and Evans, T., eds., op cit., Discretion and the Quest for Controlled Freedom, pp. 143 Basingstoke: Macmillan, op cit.

[63] Wolfson, D. J. 2020. Life Chances Revisited, Archives of Psychology (4): 1: issue 3, August 2020. 